\title{
Useful Advice and Good Arguments
}

\author{
RiCHARD FeLdMAN
}

\author{
University of Rochester
}

\begin{abstract}
Brian Huss argues that the consensus theory of argumentation is as good as, or better than, the epistemological approach at giving useful real-world advice about arguments. I describe these two ways of theorizing about arguments, describe the advice that Huss thinks the two theories can offer, make a case largely by means of examples for the view that the epistemological approach does yield useful realworld advice, and then formulate and respond to Huss's arguments. I conclude with a few brief comments on consensus and arguments.
\end{abstract}

\begin{abstract}
Résumé: Brian Huss soutient que la théorie d'argumentation fondée sur le consensus est aussi bonne ou même meilleure que la théorie épistémologique pour donner des conseils pratiques sur les arguments. Je décris ces deux approches, ainsi que les conseils que Huss pense qu'elles peuvent offrir. J'emploie principalement des exemples pour avancer que l'approche épistémologique produit des conseils utiles, ensuite je formule et évalue les arguments de Huss. Je termine avec quelques brefs commentaires sur le consensus et les arguments.
\end{abstract}

Keywords: Huss, consensus, consensus theory of argumentation, epistemological theory of argumentation, advice, good arguments.

\section{Introduction}

In "Useful Argumentation: A Critique of the Epistemological Approach," Brian Huss argues that a central goal of theories of argumentation is to give useful, real world advice, and that, on this measure, "the consensus theory looks more promising than the epistemological approach." (274)' In this commentary, I will describe these two ways of theorizing about arguments, describe the advice that Huss thinks the two theories can offer, make a case largely by means of examples for the view that the epistemological approach does yield useful real-world advice, and then formulate and respond to Huss's arguments. I will conclude with a few brief comments on consensus and arguments.

\section{Two Theories of Argumentation}

According to Huss, the consensus theory of argumentation consists in two main rules, one concerning premises and the other concerning inferences. ${ }^{2}$ The rule governing premises is the following: A participant in a discussion may properly use as a premise only propositions "that all parties to the discussion believe to begin with. Anything in the set of jointly-accepted propositions may be used by any 
participant as premises in an argument, and anything outside that set may not be used."(263) Similarly, only "inferences or inference types that are deemed acceptable by all parties may be used by any participant in presenting an argument."(263)

The epistemological theory, in contrast, focuses on epistemological considerations such as knowledge and justification. Huss says that this approach "holds that proper argumentation produces knowledge or epistemically justified belief for those who partake in the argument."(261) He does not explicitly state what rules or principles the view is committed to, but a plausible account is that it holds that a proper argument is one that has justified premises and proceeds by justified patterns of inference. Obviously, there are details that need to be worked out concerning this approach. For example, there are difficult questions about whether a pattern of inference is justified for a person only if the person has a justified belief to the effect that it is a proper pattern or whether some weaker condition will suffice. I will not address such details here since they will not matter in the discussion that follows.

As described in the previous two paragraphs, the consensus theory states rules describing what a person may use in a proper argument, whereas the epistemological approach identifies the standards for what a good (or proper) argument is. I will assume that, in the relevant sense of "may", what a person may do when arguing is determined by what constitutes a proper argument. That is, a person may use a premise in an argument just in case the premise is a proper one. Thus, we can formulate the two approaches in terms of their proposed rules about the premises and inference patterns that may be used in proper argumentation. These rules will be stated in terms of what it is proper for a person engaged in a particular argumentative discussion to do. Focusing on just the premises, the rule for the consensus theory is:

C. A premise, $P$, is a proper premise for a participant, $S$, in argumentative discussion $D$ to use iff $P$ is accepted by all parties to $D$.

Huss never explicitly states a corresponding rule for the epistemological theory, but it is reasonably clear that he takes it to be something such as:

E. A premise, $P$, is a proper premise for a participant, $S$, in argumentative discussion $\mathrm{D}$ to use iff $\mathrm{S}$ is justified in believing $\mathrm{P}$.

There is, however, no necessary connection between the thought that the idea of a good argument is to be understood in epistemological terms and the thought that (E) provides a correct account of which premises are appropriate for use in discussions. One could stick to the general epistemological framework, yet argue that a proper premise to use in a discussion is one that all parties to the discussion are justified in believing. Other broadly epistemological views are possible as well, appealing to other suitable epistemic properties. For example, one might hold that it is proper to use premises justified for most experts about a topic, or justified for most parties to a particular discussion (thus preventing lone ill-informed people from holding back discussion), and so on. 


\section{Advice}

Huss says that a theory about argumentation should yield "real-world advice that people can actually use when engaging in argument."(261-262) In the introduction to his paper, he says that he will argue that the epistemological approach does not have advantages over the consensus theory in this regard. By the end of the paper, his claim is a stronger one: in terms of giving advice "the consensus theory looks more promising." (274) The intervening discussion seems to slide between these two claims. The difference between these two claims will make some difference in the discussion that follows.

To assess Huss's claims, it will be necessary to get clear about just what advice the theories offer. As they were formulated in section I, the theories do not explicitly give advice at all. Instead, they state conditions on what is proper in argument. Presumably, there is advice that correlates with the principles about what is proper. Each theory advises the use of the premises and inferences that it deems proper. Thus,

C-ADVICE: In an argumentative discussion, use only premises and inference patterns that all parties to the discussion accept.

E-ADVICE: In an argumentative discussion, use only premises and inference patterns that you are justified in believing/using.

These principles do not offer advice about which of the many premises meeting the specified conditions to use. Suppose that a person is engaged in argumentative discussion and wishes to adhere to C-ADVICE. The person would know that he should not use premises that are not accepted by all parties to the discussion. But there may be many premises that all parties to the discussion accept. C-ADVICE does not provide any basis for choosing which of these accepted premises to use. An analogous point applies to E-ADVICE. Presumably, the consensus theory would recommend using accepted premises that will lead, by agreed upon rules of inference, to conclusions relevant to the topic under discussion. The epistemological theory, in contrast, would recommend using justified premises that lead, by justified rules of inference, to the same sort of conclusion.

For the reasons mentioned at the end of section 1, epistemological theorists need not offer the advice mentioned in E-ADVICE. They could instead advise the use of premises and inference patterns justified for all parties to a discussion, or premises and inference patterns justified for the person (or persons) with whom one is arguing. For that matter, a person could accept an epistemological account of what a good argument is, yet advise people to use whatever will best accomplish their goals. This can include using bad arguments, unjustified premises, or whatever else will best lead to the satisfaction of those goals. However, in order to give Huss's view a fair hearing, I will assume for now that epistemological theory does endorse something along the lines of E-ADVICE. 


\section{Some Advice From an Advocate of the Epistemological Approach}

As noted, Huss thinks that the epistemological theory cannot be the basis for useful advice for those engaged in argumentation. He does present an argument for this view, and I will turn to it in the next section. Before doing that, however, I will consider in slightly more detail the sort of advice I think that a defender of the epistemological approach might give.

In thinking about advice about how to engage in argument, it is useful to keep in mind two preliminary points. First, presumably, what is under discussion is general advice about how to proceed in arguments rather than specific advice regarding particular arguments. One could imagine an "argument coach" whispering advice in someone's ear: "Use premise P1 here rather than P2. P1 better supports your conclusion than P2." Clearly, such advice could be given. But that is not the sort of thing Huss has in mind.

Second, we are not to think of the advice giver as a participant in the discussions the advice is about. Thus, for example, we can think of the advice giver as an instructor in critical thinking, offering advice to students who will engage in argument outside of the class. Were the interaction with the students an argumentative discussion to which these rules apply, then the consensus theory would have the bizarre implication that the instructor should only say things that all the students already believe or that follow from things they already believe. This would reduce the instructor's ability to teach the students anything new.

In my view, the idea that the epistemological theory cannot be the basis for useful advice for people engaged in argument is plainly false. The evidence for this is the fact that it has been done. A self-serving example is a textbook I have written. ${ }^{3}$ The book begins by spelling out the underlying concepts of the epistemological approach to arguments, and then it turns to a detailed discussion of a method for identifying, reconstructing, and evaluating arguments. The material is presented primarily for those analyzing arguments encountered in written material, but the points it covers can in most cases easily be extended to cover the presentation of and response to arguments by those engaged in argumentative discussion. In the book's 460 pages I did the best I could to convey useful advice about how to deal with arguments. There are numerous other texts, differing from mine in various ways but nevertheless accepting the general framework of the epistemological approach. Some of them are full of useful advice about arguments. ${ }^{4}$

As we will see in the next section, Huss's main arguments turn on the status of advice of the sort found in E-ADVICE. However, far from being limited to endorsing only the generic point contained in that principle, advocates of the epistemological approach can go on at length-for a semester or for 460 pages or more-spelling out in greater detail what it is for a premise to be justified (as opposed to, say, simply being firmly believed), showing which sorts of premises provide justification for particular kinds of conclusions, and helping people to see how to translate the 
sometimes sloppy or incomplete things that are typically said or written into arguments that are clear enough to evaluate.

It may be useful to describe in slightly more detail some of the kinds of advice I have in mind. One theme in my textbook involves the recommendation that one reconstruct arguments in ways that make them conform to relatively simple patterns of inference. Doing this often forces people to get clearer about the unstated assumptions linking their explicit premises and conclusions. Since these implicit premises are sometimes questionable or plainly false, bringing them to light is a useful element of argument analysis. Uncovering them can lead people to investigate them further, sometimes with the result that they are established or refuted.

In addition to including implicit premises in arguments, I advise people to drop unused premises from arguments. This is important, since the presence of an unused premise can lead to unnecessary and sometimes complex discussion and it can also lead to mistaken evaluations of arguments. This is apt to happen when people reject an argument because an unnecessary premise it contains is false.

These two pieces of advice are not tied uniquely to an epistemological approach to argumentation. There is nothing to prevent someone who thought of arguments purely in terms of more traditional logical categories-validity and soundnessfrom giving the same advice. It is less clear that defenders of the consensus approach have any clear basis for these recommendations. If omitting needed premises or including unnecessary premises will help lead to agreement, then, from that perspective, there is no particular reason to modify one's argument. The consensus theory seems to provide no basis for any advice beyond C-ADVICE.

There is additional advice that does have a more specifically epistemological slant. For example, if you are interested in discovering the truth about a topic, it is important to rely on premises that you have good reason to believe. The concept of justified belief is not one that students and others initially grasp all that clearly. It is easy to conflate epistemically justified belief with strong conviction and it is common to conflate pragmatic reasons for belief with epistemically strong reasons. People sometimes attach more significance to the fact that a belief is widely accepted than they should (which is not to say that widespread acceptance is always epistemically irrelevant). There is, therefore, considerable work to be done in clarifying the concept of epistemic justification. When this work is done, and expressed in the form of advice about the sorts of premises to use in arguments, the resulting advice can be useful. Such advice may well differ substantially from the advice offered by consensus theorists, since people can agree on things that lack epistemic justification.

Similar considerations apply to inference patterns. People can be engaged in a good faith effort to discover the truth about a topic, yet accept inference patterns that are not worthy of acceptance. Arguments about statistical, causal, and moral issues are often especially troublesome. It can be particularly useful to help people to see that a few positive instances are insufficient to confirm a generalization or 
that there are complexities involved in drawing causal conclusions from statistical premises. The consensus theory does not provide any clear basis for advising people to avoid tempting bad inferences in these domains in cases in which they are engaged in discussion with others who also accept them. Of course, if one is in an argumentative discussion with a person who is tempted by these inferences, one can try to find some mutually accepted premises that will lead to the conclusion that the inferences are not truth preserving. But, when giving advice, consensus theorists are limited to C-ADVICE and thus have no basis for advising people to do anything other than use whatever (possibly mistaken) inferential patterns they and their co-discussants accept. Their theory apparently denies the existence of any standard beyond mutual consent.

The difference between the epistemological theory and a theory that emphasizes more traditional logical concepts such as validity and soundness, rather than epistemic concepts such as justification, is less stark than the difference between the epistemological theory and the consensus theory. One way to see why the epistemological theory captures something important about the assessment of arguments, something missed by non-epistemological theories, emerges from consideration of simple arguments such as the following. Suppose that I have tossed a coin and not seen whether it landed with the head side up $(\mathrm{H})$ or the tail side up (T). Consider the following two arguments:
1. $\mathrm{H}$ or $\mathrm{T}$
1. $\mathrm{H}$ or $\mathrm{T}$
2. $\sim \mathrm{T}$
2. $\sim \mathrm{H}$
3. $\mathrm{H}$
3. T

One of these arguments is a sound argument. However, under the conditions specified, neither argument provides one with a good basis for accepting its conclusion. The reasons for this concern the epistemic status of the second premise of each argument. The epistemological theory properly brings this out, whereas a more purely logical approach to arguments does not. ${ }^{5}$ It is inadvisable to use either argument, even though one of them is sound.

I think, then, the facts strongly support the conclusion that those advocating the epistemological approach to arguments can give useful advice to those engaged in argumentation. I have just briefly described some such advice, and readers can easily imagine what much more such advice would be like. I turn next to Huss's arguments concerning the inability of the epistemological theory to give useful advice.

\section{Huss's Argument}

A central theme in Huss's paper is that there is something objectionable about appealing to "external" standards in theories of argumentation. External standards are standards that do not depend upon what the participants to a discussion think. 
They contrast with internal standards. The consensus theory appeals to internal standards, since a person can tell whether an argument meets its proposed standards simply by examining the beliefs of those engaged in the discussion. The epistemological theory appeals to external standards, since the acceptability of a premise or inference pattern is not simply a function of what a person believes. This line of thought may be taken to support Huss's stronger claim, that the epistemological theory is inferior to the consensus theory.

Huss does not spell out very clearly just what he thinks is wrong with external standards. I will offer a general comment on the topic here. Suppose someone advised a person to use only premises that will be widely accepted 500 years from now. One might regard this as not very helpful advice, since one often does not know which premises satisfy it. Similarly, one might think, advising people to use premises that are true, or known, or justified is similarly pointless, since they will often not know which premises have those properties. But this thought is mistaken. People can have good reason to think that certain premises meet these epistemic standards, and it makes sense to advise them to use premises that meet them. Perhaps they will sometimes try but fail to do what they have been advised to do. It does not follow that the advice is deficient. If the only acceptable advice is advice that can always be followed successfully, then the consensus theory also offers unacceptable advice. This is because one can be mistaken about what premises and inference patterns are agreed upon by all parties to a discussion. There is just no good reason to prohibit "external" standards.

The main argument Huss develops in his paper turns on a distinction between following advice and merely acting in accordance with advice. The most charitable reading of Huss's paper requires taking this argument to support the weaker conclusion, that the epistemological theory is no better than the consensus theory in terms of offering useful advice. Speaking of E-ADVICE, he writes:

The problem with this piece of advice is that if each of the participants to a critical discussion honestly believes everything they say and honestly believes that all of their inferences are valid (in the broad sense), then they will act in accordance with this advice, regardless of whether it is offered. They won't follow the advice, however, because to follow a piece of advice is to make sure that you do things you might not ordinarily do or to make sure that you don't do things that you might otherwise be tempted to do. If, on the other hand, the participants to a critical discussion do not honestly believe everything they say or do not honestly believe that their inferences work, then they are not honest participants. And when the participants are not honest, it's hard to see how they can be said to be engaged in critical discussion in the first place. In other words, honest discourse in which all of the participants believe that everything they say is true and epistemically justified is constitutive of critical discussion.(265)

Huss here reasons that if a person is already engaged in critical discussion, then the person is already using justified premises (or premises the person takes to be 
justified). In that case, the epistemological theorist's advice will not change their behavior, and thus is pointless. He goes on to say that if, on the other hand, the person is not engaged in critical discussion (i.e., is not using premises the person takes to be justified), then the epistemological theorist can offer advice that might move the person to change. But, he claims, this advice will be the same as the consensus theorist's advice. That is, everything that the epistemological theorist can say to such a person, the consensus theorist can say as well. In this case, the epistemological theorist is no better off than the consensus theorist. Thus, we get Huss's conclusion: either the advice offered by the epistemological theorist's advice "fails to motivate, or it motivates but is no different from the advice yielded by the consensus theory." (267) The epistemological theory therefore has no advantage over the consensus theory.

I believe that this reasoning goes wrong in several ways.

First, it is puzzling for a defender of the consensus theory to require that participants in discussions use only premises that they believe are justified. This seems to appeal to a conception of justification that goes beyond anything determined by consensus. In fact, it seems to import illegitimately into the consensus theory the very sort of consideration that is prominent in the epistemological theory. One line of thinking that might lead one to advocate a consensus theory relies on the idea that there is no such thing as "objective" justification; the closest legitimate notion is agreement or consensus. But Huss is obviously precluded from defending the consensus theory in this way.

A more crucial point concerns Huss's claim that if people "honestly believe" their premises, then they will act in accordance with the advice that they use justified premises. It is not entirely clear to me what Huss means by "honestly believe." As I understand the phrase, people can honestly believe things that they are not justified in believing. They can believe things in an effort to learn the truth, with no element of self-deception or willful distortion, yet without justification. Some of the ideas discussed in section 3 help to illustrate how this can happen.

As my discussion in section 3 showed, one can get well beyond the generic advice contained in E-ADVICE and give far more specific advice of the sort described there. People can be sincerely trying to use only justified premises and good forms of inference, but fail to do so. People may have the tendency to commit the gambler's fallacy or to generalize from salient but unrepresentative instances or to make any number of notable inferential errors. Defenders of the epistemological approach are free to explain all of this to people, and thus to try to help them get past these errors. To think that their advice is simply the generic idea in E-ADVICE seems to presuppose a remarkably implausible kind of epistemic perfection among people who honestly engage in critical discussion. The final sentence in the passage just quoted says that it is constitutive of critical discussion that people say only what they believe is justified. But it does not follow that it is constitutive of critical discussion to say only what actually is justified or to follow 
all the more detailed pieces of advice that can be offered. On Huss's view, anyone who slips up on these details is not even engaged in critical discussion. Either this is just mistaken or much of what passes for critical discussion is in fact not critical discussion. In the latter case, the epistemological approach to arguments can offer advice that will help people who are trying unsuccessfully to engage in critical discussion to succeed in doing so. Epistemologically oriented advice can motivate changes in behavior among people honestly engaged in argument.

Finally, Huss is mistaken in claiming that the consensus theorist and the epistemological theorist will offer the same advice to those who are not already trying to use justified premises. Suppose a person engaged in an argument is using an unjustified premise. As an advice giver, the consensus theorist should recommend to the person the general principle that premises agreed upon in that discussion be used. But the consensus theorist need not be a party to that argumentative discussion, and thus the consensus theorist's own views are not relevant to determining which premises or inferences can be used in the discussion. Huss's claim here apparently conflates the role of someone giving general advice about how to conduct arguments with a role that requires participation in a particular argument. Consensus theorists must depart from their theory if they give the advice epistemological theorists give. They can, of course, adopt the epistemological theory and give its advice. But their theory itself legitimizes giving C-ADVICE and nothing more.

I conclude that Huss's argument fails. His central premise-that it is constitutive of rational argument that those engaged in rational argument must be using premises they take to be justified - is a premise that does not fit well with a central rationale for the consensus theory. In addition, it is not true that defenders of the epistemological theory can only give trivial advice to those who are trying to use justified premises and it is not true that the consensus theory and the epistemological theory give the same advice in other cases.

\section{Arguments, Consensus, Justification, and Advice}

I will conclude with some more general comments on the issues raised in Huss's paper. The connection between one's views about good arguments and advice is far murkier than the discussion so far suggests. Defenders of the epistemological approach are not limited to giving advice of the sort Huss has in mind. Imagine someone, perhaps a beginning student, asking an instructor for advice about how to proceed in an argumentative discussion. Were that instructor like me, he or she would ask the student what the primary goal of the discussion was. There are numerous distinct but sensible objectives the participants may have. They may be attempting, to the best of their ability, to figure out the truth about their subject matter. They may be attempting to reach agreement. They may be trying to identify the arguments on the topic that will best persuade others of a conclusion that participants to the discussion have already agreed upon. They may have any number of other goals. 
Huss seems to assume, without justification so far as I can tell, that the goal, or the proper goal, of argumentation is to achieve consensus. One place in which he alludes to this claim is in a discussion of the connection between accounts of the nature of argumentation and accounts of the right way to go about it. He wants to defend the idea that "in many cases a practice is best explained by offering advice on how to do it."(270) In the course of explaining this, he writes:

Once you know the aim of argumentation (i.e., consensus) and the methods used to achieve that aim (e.g., present arguments that don't make use of unargued-for assumptions your co-discussants deny), you know how to engage in good argumentation, and you thereby know what good argumentation is. (270-271)

That consensus is the aim of argumentation strikes me as an extremely implausible premise. (By Huss's standards, then, he should not use this premise in discussion with me.) Consensus is, of course, often a desired outcome of rational discussion. But you can also seek understanding and clarification of alternative points of view. You can engage in discussion to find out if, as you see it, there really is anything compelling in some view you initially reject. For example, an opponent of capital punishment might discuss the topic with a proponent in an effort to see if all the arguments in its favor ultimately depend upon premises having to do with its (alleged) deterrent effect. You can engage in argumentation in order to see more clearly whether a disputed premise really does support a proposed conclusion. It is possible, perhaps, to recast the point of all such discussions so that they are not "really" about the central topic (e.g., capital punishment) but instead are about the secondary topic (e.g., whether all the arguments depend upon the disputed premise). And then one can say that the point of the discussion is to achieve consensus on this topic. But, once again, achieving consensus on the topic may not be the only goal, or even the main goal, of the participants. They may seek instead to understand the matter as well as they can.

If the goal really is consensus, then it is very hard to see why any of the standard logical and epistemic standards placed on arguments really do apply. Huss discusses an example concerning a group of people all of whom endorse the gambler's fallacy. The consensus approach seems to endorse their use of arguments conforming to that pattern as good arguments. It is true that they may reach consensus in that way. It is difficult to see what else is to be said in favor of the use of that fallacious pattern of argument. This seems to be a serious flaw of the consensus approach.

But the consensus approach is open to additional objections as well. Suppose that you are in a discussion about some proposition, P. You believe $P$ and the other person initially denies it. You also know that this person accepts some false premises or some mistaken inferential patterns that will seem (to him) to support P. If consensus concerning $P$ is your goal, then it would be a good idea to make use of this argument that you yourself do not accept. To avoid such results, one might say, as other consensus theorists have, that the goal is to achieve consensus 
rationally. But, as Huss correctly says in rejecting this view, this effectively abandons the consensus approach since it introduces a standard external to the actual views of the people engaged in conversation (263). One can also say, as Huss's consensus theorist does, that there should be consensus about the premises. But it is far from clear why this restriction is plausible if consensus concerning $\mathrm{P}$ is the goal.

No doubt there are times when consensus is a suitable goal. And no doubt there are times when the suitable way to proceed in argument is to try to use premises and argument patterns accepted by your conversational partners in an effort to show that they lead to the conclusion you yourself initially believe. In such cases, your goal is, in effect, to show someone that he or she is already committed to the conclusion you believe. In some such cases, sticking to arguments that meet the standards set by an epistemic theory of argument will not serve your purposes. It is also true that sticking to premises that your partners accept will sometimes prevent you from identifying and assessing the arguments that give you best chance at determining the truth of the topic under discussion. The epistemological approach to arguments, when spelled out in suitable detail, provides the best advice about how to achieve that determination. It is a useful theory. ${ }^{6}$

\section{Notes}

${ }^{1}$ Here and in the following bracketed numbers refer to the respective pages of Brian Huss's contribution to this issue.

${ }^{2}$ For an influential statement of this view, see Frans H. van Eemeren \& Rob Grootendorst $(A$ Systematic Theory of Argumentation. The pragma-dialectical approach. Cambridge: Cambridge University Press 2004.)

${ }^{3}$ Reason and Argument ( $2^{\text {nd }}$ Edition), Prentice-Hall, Upper Saddle River, NJ. 1999.

${ }^{4}$ One such text is Thomas J. McKay's Reasons, Explanations and Decisions, Wadsworth, Belmont, CA, 2000.

"I discuss this point in greater detail in "Good Arguments", in Frederick F. Schmitt, ed. Socializing Epistemology, Rowman \& Littlefield, Lanham, MD, 1994. See especially section I.

- I am grateful to Christoph Lumer for very helpful comments on a draft of this paper.

Richard Feldman Department of Philosophy University of Rochester Rochester, NY 14627, USA 